\title{
Role of Oct4 in maintaining and regaining stem cell pluripotency
}

Guilai Shi', ${ }^{1,3}$ and Ying Jin ${ }^{1,2 *}$

\begin{abstract}
Pluripotency, a characteristic of cells in the inner cell mass of the mammalian preimplantation blastocyst as well as of embryonic stem cells, is defined as the ability of a cell to generate all of the cell types of an organism. A group of transcription factors is essential for the establishment and maintenance of the pluripotent state. Recent studies have demonstrated that differentiated somatic cells could be reverted to a pluripotent state by the overexpression of a set of transcription factors, further highlighting the significance of transcription factors in the control of pluripotency. Among these factors, a member of the POU transcription factor family, Oct4, is central to the machinery governing pluripotency. Oct4 is highly expressed in pluripotent cells and becomes silenced upon differentiation. Interestingly, the precise expression level of Oct4 determines the fate of embryonic stem cells. Therefore, to control the expression of Oct4 precisely, a variety of regulators function at multiple levels, including transcription, translation of mRNA and post-translational modification. Additionally, in cooperation with Sox2, Nanog and other members of the core transcriptional regulatory circuitry, Oct4 activates both protein-coding genes and noncoding RNAs necessary for pluripotency. Simultaneously, in association with transcriptional repressive complexes, Oct4 represses another set of targets involved in developmental processes. Importantly, Oct4 can re-establish pluripotency in somatic cells, and proper reprogramming of Oct4 expression is indispensable for deriving genuine induced pluripotent stem cell lines. In the past several years, genome-wide identification of Oct4 target genes and Oct4-centered protein interactomes has been reported, indicating that Oct4 exerts tight control over pluripotency regulator expression and protects embryonic stem cells in an undifferentiated state. Nevertheless, further investigation is required to fully elucidate the underlying molecular mechanisms through which Oct4 maintains and reinitiates pluripotency. Systemic and dynamic exploration of the protein complexes and target genes associated with Oct4 will help to elucidate the role of Oct4 more comprehensively.
\end{abstract}

\section{Introduction}

During mammalian embryogenesis, early embryonic cells progressively differentiate from a pluripotent state into distinct cell lineages. Concomitantly, they gradually lose their developmental potential [1]. Pluripotency, which is a characteristic of cells in the inner cell mass (ICM) of the preimplantation blastocyst, is defined as the ability of a cell to differentiate into all of the cell types of an organism. The state of pluripotency is transient in vivo; however, embryonic stem cells (ESCs) derived from the ICM of the blastocyst can maintain pluripotency indefinitely in vitro. Pluripotency has been shown to be

*Correspondence: yjin@sibs.ac.cn

${ }^{2}$ Shanghai Institute of Stem Cell Research, Shanghai JiaoTong University School of Medicine, 225 South Chongqing Road, Shanghai 200025, China

Full list of author information is available at the end of the article controlled through an extensive transcriptional network. Remarkably, differentiated somatic cells can be reprogrammed to a pluripotent state by the overexpression of defined transcription factors (Oct4/Sox $2 / \mathrm{Klf} 4 / \mathrm{c}-\mathrm{Myc}$ or Oct4/Sox $2 / \mathrm{Nanog} / \mathrm{Lin} 28$ ) [2,3]. Among these transcription factors, Oct4 plays a key role in both maintaining and re-establishing pluripotency.

Oct4 (encoded by Pou5f1, also known as Oct3, Oct3/4) was first identified in mice as an ESC-specific and germline-specific transcription factor [4-6]. In humans, OCT4 is the product of the OTF3 gene, and three isoforms, OCT4A, OCT $4 B$ and OCT $4 B 1$, have been reported [7]. Among these isoforms, only OCT4A which shares $87 \%$ amino acid sequence identity with mouse Oct 4 - has been demonstrated able to maintain stemness in pluripotent stem cells; it is referred to as OCT4 in the vast majority of reports. The Oct4 protein comprises three domains: a central POU (Pit-Oct-Unc) domain for DNA binding, an $\mathrm{N}$-terminal transactivation 
domain and a C-terminal domain, which appears to be a cell type-specific transactivation domain. Oct4 belongs to the POU transcription factor family, in which the members control the expression of their target genes through binding an octameric sequence motif of an AGTCAAAT consensus sequence [8].

During mouse embryonic development, Oct 4 is highly expressed in pluripotent embryonic cells, as well as cells of the germline, and its expression rapidly decreases upon differentiation. Analysis of upstream regulatory elements of the Oct4 genomic locus identified a proximal enhancer and a distal enhancer, in addition to a TATA-less proximal promoter [9]. Interestingly, the proximal enhancer and the distal enhancer function at different developmental stages: the proximal enhancer functions in the epiblast and epiblast stem cells, while the distal enhancer plays roles in the ICM, primordial germ cells and ESCs. Nordhoff and colleagues compared human, bovine and murine Oct4 upstream sequences and found four conserved regions (CR1 to CR4), showing possible involvement in Oct4 expression [10]. For more details on this topic, we refer readers to several excellent reviews $[11,12]$.

Functionally, Oct4 is essential for early embryonic development, although it is not required for mouse somatic stem cell self-renewal [13]. In the absence of Oct4, embryos die at the time of implantation because of a lack of pluripotent ICM cells [14]. Oct4 is therefore considered a master regulator for the initiation and maintenance of pluripotent cells during embryonic development. Interestingly, the precise expression level of Oct4 is a critical determinant of ESC fates, and their pluripotent potential can be sustained only when the Oct4 expression level is maintained within a normal range [15-17]. Reducing Oct4 expression by one-half induces ESCs to differentiate into trophoblasts, while less than twofold overexpression of Oct4 triggers ESC differentiation into primitive endoderm and mesoderm [17]. In line with this, transforming growth factor betainduced transient Oct4 upregulation can promote cardiac mesoderm differentiation, supporting the role of the level of Oct4 in regulating pluripotency and differentiation [18]. Moreover, the recent discovery of an essential role of Oct4 in reprogramming somatic cells into pluripotent cells further highlights its irreplaceable function in establishing pluripotency.

In the present review, we first summarize recent progress in understanding how the regulation of Oct4 expression is achieved at multiple levels, and then describe how Oct4 acts with its partners to regulate the expression of its target genes in maintaining pluripotency. Finally, we briefly review the role of Oct4 in regaining pluripotency. Owing to limitations of space, we cannot cover all related studies and apologize to the authors whose contributions are not mentioned in this review.

\section{Tight control of Oct4 expression at multiple levels}

Achieving precise control of Oct4 expression is a key issue for the maintenance of as well as the re-establishment of pluripotency, and many players participate in this process at multiple levels (Figure 1). First, a defined chromatin state is essential for Oct4 expression. In undifferentiated ESCs, the Oct4 locus is hypomethylated and packaged with nucleosomes containing highly acetylated histone H3 (Lys 9, Lys 14) and dimethylated or trimethylated histone H3 (Lys 4) [19]. The locus, however, undergoes a series of epigenetic modifications, leading to the repression of Oct4 expression upon the induction of differentiation. In addition to deacetylation, G9amediated histone $\mathrm{H} 3$ methylation on Lys 9 recruits heterochromatin protein 1 to confer a compact chromatin configuration [19]. Subsequently, permanent inactivation of Oct4 is achieved when two de novo methyltransferases, Dnmt3a and Dnmt3b, function synergistically to methylate the promoter of Oct4 [20]. In addition, Cdk2ap1 was shown to promote Oct4 promoter methylation and to downregulate Oct4 expression during mouse ESC differentiation through its direct interaction with the methyl DNA-binding protein Mbd3 [21]. Additionally, Paf1C, a component of the Paf1 complex, associates with RNA polymerase II and binds to the promoter of Oct4 to maintain a transcriptionally active chromatin structure [22]. The epigenetic regulation of the chromatin state therefore plays an important role in the control of Oct4 expression and the proper reprogramming of somatic cells to overcome repressive modifications. Indeed, inhibitors of G9a and DNA methyltransferase have been shown to promote the reprogramming efficiency in a variety of cell types [23].

At the transcriptional level, direct binding of transacting regulators to the Oct4 locus also plays a critical role in the modulation of Oct4 expression. Several members of the orphan nuclear receptor family have been recently found to participate in the control of Oct4. expression, supporting an earlier report that the nuclear receptors PAR-1/COUP-TFII, EAR-3/COUP-TFI and $\mathrm{RAR} / \mathrm{RXR}$ regulate the Oct4 promoter activity in mouse embryonal carcinoma cells [24]. Steroidogenic factor-1 and estrogen-related receptor $b$ (Esrrb) were shown to directly activate the transcription of human OCT4 and mouse Oct4, respectively, to sustain pluripotency in ESCs $[25,26]$. Another orphan nuclear receptor, LRH-1 (also known as Nr5a2), was shown to bind the steroidogenic factor-1 responsive element in the proximal promoter and the proximal enhancer of Oct4 to maintain Oct4 expression at the epiblast stage of embryonic development [27]. Additionally, germ cell nuclear factor represses Oct4 expression by specifically binding with the proximal promoter and is necessary for confining Oct4 expression to the germline [28]. Interestingly, the orphan nuclear 


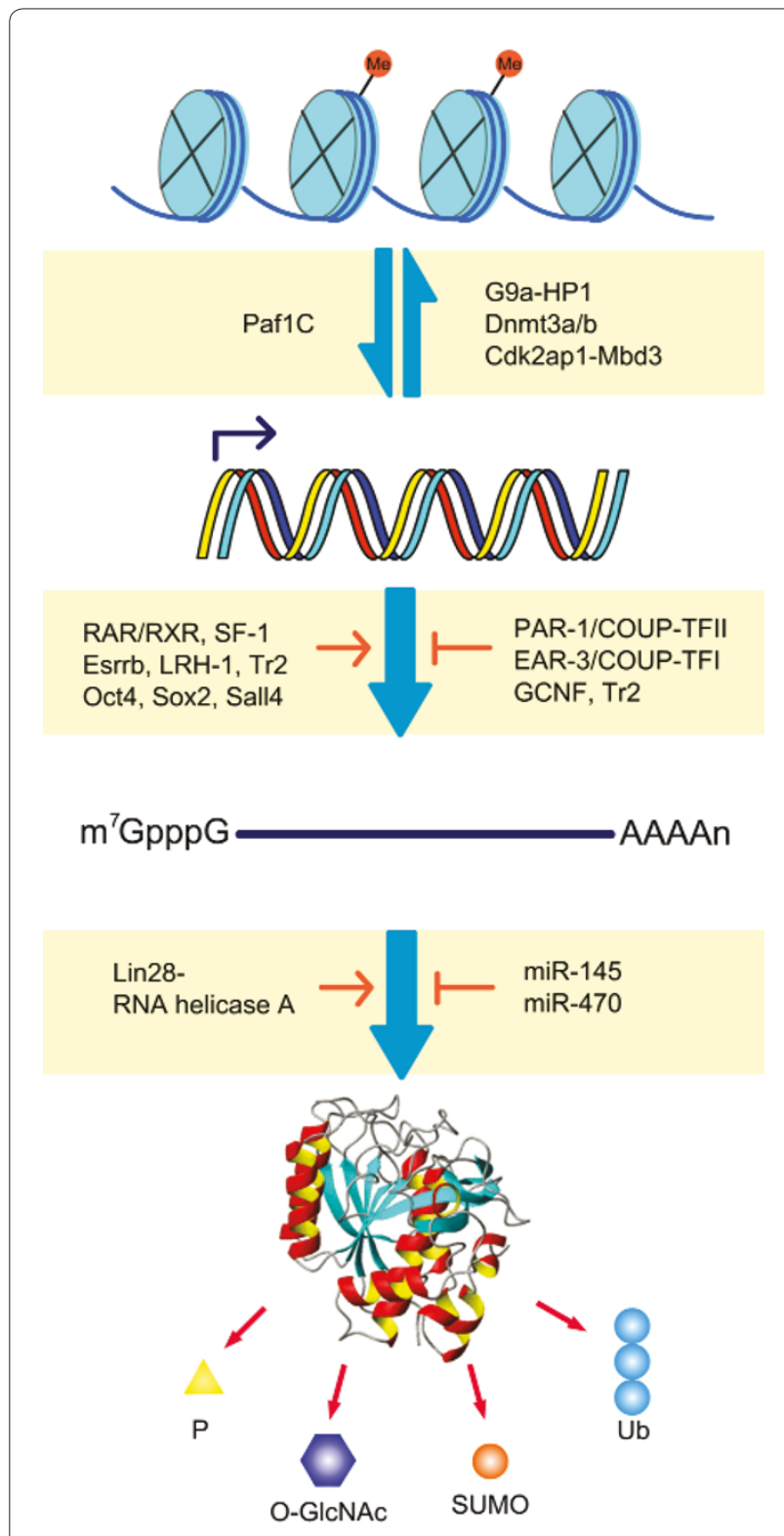

Figure 1. Precise control of Oct4 expression at multiple levels. The chromatin modifier Paf1C increases Oct4 expression by relaxing the compact chromatin, while G9a adds a repressive mark and recruits heterochromatin protein 1 (HP1), leading to a compact chromatin configuration. Subsequently, Dnmt3a/b methylates the Oct4 promoter to permanently inactivate Oct4 expression. This process is enhanced by Cdk2ap1 interacting with Mbd3. At the transcription level, two sets of transcription factors and nuclear receptors function antagonistically: one set (including Esrrb, LRH-1, Oct4, Sox2 and Sall4) activates Oct4 expression, while the other set (including germ cell nuclear factor (GCNF) and Tr2) represses its expression. After transcription, Lin28 recruits RNA helicase A to promote the translation of Oct4 mRNA, while miRNAs (including miR-134 and miR-470) cause its decay. In addition, several posttranslational modifications (such as ubiquitination (Ub), sumoylation and phosphorylation (P)) are added to the Oct4 protein after it is translated and influence the activity and stability of Oct4 proteins. SUMO, small ubiquitin-related modifier. receptor Tr2 alternates between being an activator and a repressor of Oct4 expression depending on its phosphorylation, sumoylation and associated coregulators $[29,30]$. Furthermore, pluripotency factors form a regulatory circuitry consisting of autoregulatory and feedforward loops [31,32]. For instance, the distal enhancer of Oct4 has a composite Oct-Sox element, and Oct4 and Sox2 bind to this element to synergistically activate the expression of Oct4 [33]. Sall4, a spalt family member, also modulates ESC pluripotency through transcriptional control of Oct4 [34,35]. The coordinated action of these key factors is therefore fundamental for the maintenance of pluripotency.

miRNAs play important roles in the post-transcriptional regulation of Oct4 expression. $\mathrm{Xu}$ and colleagues reported that miR-145 directly repressed the 3 ' untranslated region of OCT4 mRNA during human ESC differentiation. Interestingly, the promoter of miR-145 was also observed to be bound and inhibited by OCT4 in human ESCs, uncovering a double-negative feedback loop for OCT4 and miRNA expression [36]. Although miRNAs usually target the 3 ' untranslated regions of mRNAs, miR-296, miR-470 and miR-134 were found to be upregulated in differentiated mouse ESCs and to target the coding sequences of Oct4, Nanog and Sox2 in various combinations [37]. In addition to these negative regulators of Oct4 during ESC differentiation, Qiu and colleagues recently found that $\operatorname{Lin} 28$ - which is a repressor of miRNA processing - bound OCT4 mRNA directly within its coding region and recruited RNA helicase A to promote the translation of OCT4 in human ESCs [38]. There may still be many other regulators functioning at the post-transcriptional level that remain to be found.

The stability and activity of Oct4 proteins are subject to modifications at the post-translational level. An early study suggested that the differential phosphorylation of Oct4 might affect the transactivation ability of the Oct4 carboxyl-terminal transactivation domain [39]. A recent study reported that human OCT4 can be modified by the monosaccharide $\mathrm{O}$-linked $\quad \beta$ - $N$-acetylglucosamine (O-GlcNAc), which regulates the activity of a wide variety of cellular proteins [40]. Notably, the enzyme catalyzing this post-translational reaction, Ogt, was found in Oct4-associated protein complexes in two recent independent studies [41,42]. Whether this modification regulates the OCT4 activity in ESCs, however, remains unclear. Moreover, ubiquitination is a common modification of proteins that decreases the stability of modified proteins. Our laboratory first identified a mouse HECT-type E3 ubiquitin ligase of Oct4 known as Wwp2 [43]. Subsequent research indicated that Wwp2 plays an important role in Oct4 ubiquitination and degradation during the differentiation of embryonic carcinoma cells, 
although it does not appear to affect Oct4 protein levels in undifferentiated mouse embryonic carcinoma cells and ESCs [44]. Interestingly, its human counterpart, WWP2, can ubiquitinate endogenous OCT4 proteins in human ESCs and promote its degradation through the $26 \mathrm{~S}$ proteasome [45]. Currently, there exists no definitive answer to the question of why this enzyme degrades OCT4 proteins in undifferentiated human ESCs but not in undifferentiated mouse ESCs. One possible explanation is that human ESCs represent a more developed stage than mouse ESCs [46]. In addition to ubiquitination, our group and another group found that Oct4 was a target of small ubiquitin-related modifier-1 modification and that the sumoylation resulted in increased stability, DNA binding and transactivation of Oct4 [47,48]. Ubiquitination and sumoylation appear to jointly control Oct4 proteins at an appropriate level in ESCs. We hypothesize that other types of modifications of Oct4 proteins may exist to regulate its protein level and function.

The Oct4 expression level is modulated by multiple factors and mechanisms. Continued efforts are required to elucidate the sophisticated regulatory network associated with the precise control of Oct4 expression, particularly to understand how Oct 4 expression is reactivated during reprogramming.

\section{Transcriptional targets and protein complexes associated with the function of Oct4}

Oct4 lies at the center of the mechanisms that maintain the self-renewal and pluripotency of ESCs. Oct4 mainly functions through the activation of pluripotencyassociated and self-renewal-associated genes, while simultaneously repressing genes that promote differentiation, in coordination with other pluripotency factors and coregulators. Genome-wide mapping of the binding sites of Oct4 and other ESC factors has revealed that Oct4 clusters with different but overlapping sets of transcriptional factors or coregulators at distinct genomic locations, suggesting that the function of Oct 4 in the regulation of gene expression may be modulated by various associated partners. Among the partners of Oct4, Sox2 is the best characterized. They are considered as a versatile pair of master regulators orchestrating selfrenewal and pluripotency. The regulatory elements of a large number of Oct4 target genes contain a composite Oct-Sox element separated by several nucleotides. Oct 4 and Sox 2 bind the element simultaneously and synergistically activate the expression of these genes, including Oct4 [33], Sox2 [33], Nanog [49], Fgf4 [50], Utf1 [51] and Zfp206 [52], all of which play important roles in maintaining pluripotency. Subsequent studies have shown that certain Oct4/Sox2-targeted transcription factors are themselves often components of the Oct4 interactome. For instance, Oct4, Sox 2 and Nanog have been considered to act as a core transcriptional regulatory circuitry in pluripotent stem cells, as they co-occupy a large number of their target genes [31,53,54]. Nanog could be an important target for Oct4 in maintaining pluripotency; it is required for repressing the differentiation of pluripotent epiblast cells toward extraembryonic lineages $[49,55,56]$, and its overexpression can maintain ESCs in an undifferentiated state in the absence of leukemia inhibitory factor. Additionally, Zfp206 was recently demonstrated to physically interact with Oct4/ Sox2, being a key component of Oct $4 /$ Sox 2 complexes [57]. The Oct4 transcriptional regulatory circuitry thus ensures tight control of pluripotency regulator expression and maintains ESCs in an undifferentiated state.

Several well-known Oct4 target genes - including Fgf4, Utf1, Osteopontin, Rex1, Hand 1 and $\alpha$ and $\beta$ human chorionic gonadotropin $(h C G)$ - were identified through earlier single-gene experiments using promoter-reporter or enhancer-reporter activity assays (reviewed in $[11,12]$ ). To identify Oct4 targets at a global level, high-throughput approaches such as gene-expression profiling in Oct4manipulated mouse ESCs, genome-wide chromatin immunoprecipitation assays or a combination of both have been utilized in the past several years $[32,58,59]$. These investigations identified hundreds and thousands of putative Oct4 targets. Notably, Oct4 appears to function predominantly as an activator of gene expression, although it also suppresses transcription [59]. Interestingly, Matoba and colleagues discovered a group of targets that exhibit both activation and suppression depending on the Oct4 expression level [58]. Rex1 is an example of this unique type of regulation, as at both low and high levels Oct4 represses Rex1 expression but at intermediate levels it activates Rex1 expression. This finding may be related to mechanisms underlying the requirement to keep the Oct4 level within a narrow range for the maintenance of ESCs in a self-renewal and pluripotent state [17]. In addition to mouse ESCs, chromatin immunoprecipitation-on-chip experiments have also been performed in human ESCs to reveal DNAprotein binding events involving OCT4, SOX2 and NANOG. The target genes identified frequently encode transcription factors, many of which are developmentally important homeodomain proteins [31]. Moreover, Chavez and colleagues reported the identification of a core OCT4 regulatory network in human ESCs consisting of 33 target genes by carrying out an integrated analysis of high-throughput data [60]. More recently, two groups reported the genome-wide identification of binding sites of different sets of ESC factors $[61,62]$. Their results show that genes in which the promoters are occupied by multiple factors, such as Oct4, Sox2, Nanog and Klf4, are generally active in ESCs; in contrast, genes that bind fewer or single factors tend to be inactive or repressed 
[62]. ESC-specific gene expression and the state of pluripotency are therefore orchestrated by the coordinated efforts of many key transcriptional factors and coregulators.

In addition to activating pluripotency factors, Oct 4 also prevents the differentiation of pluripotent cells by acting as a repressor of lineage-specific transcription factors. During the first cell fate-deciding event in mammalian development - the segregation of the ICM and the trophectoderm - Oct 4 is required for establishing the pluripotency of ICM cells. Oct4 forms a repressive complex with and inhibits the transcription of $C d x 2$, a transcription factor essential for trophectoderm specification [63]. In the absence of Oct4, the embryo develops to the blastocyst stage and appears to be morphologically normal. The cells in the ICM, however, differentiate into trophoblast cells without pluripotent embryonic cells [14]. Moreover, Oct4 recruits a histone H3 (Lys 9) methyltransferase, Eset, to silence the expression of trophoblast-associated genes, thus partnering with an epigenetic regulator to restrict extraembryonic trophoblast lineage potential in ESCs [64]. At the late blastocyst stage, Oct4, Sox2 and Nanog are required for the development of pluripotent epiblast cells and the restriction of the formation of primitive endoderm. A recent study by our group demonstrated that Oct4, together with Sox2 and Nanog, directly inhibits the expression of Stk40, an inducer of extraembryonic endoderm in mouse ESCs. In agreement with the notion that Oct4 functions to prevent ICM cells from differentiating into primitive endoderm, we found that ESCs depleted of Oct4 by specific interfering RNA were mainly incorporated into the extra embryonic endodermal lineages in chimeric embryos when injected into preimplantation blastocysts [16]. Furthermore, it was reported that Oct4 interacts with the DNA-binding domain of FoxD3 and represses its activation of FoxA1 and FoxA2, two critical regulators for the development of the endodermal foregut [65]. The subsequent identification of Oct4-interacting proteins by affinity purification and mass spectrometry revealed that Oct4 associated with unique transcriptional repression complexes containing Hdac1/2 and Mta1/2 in mouse ESCs [66,67], providing significant insight into the mechanism of the repression of developmental genes by Oct4.

Recently, using improved affinity tagging approaches, van den Berg and colleagues and Pardo and colleagues identified 50 and 92 putative Oct4-associated proteins, respectively, in mouse ESCs [41,42]. These two studies not only identified more detailed Oct4-centered interactome networks than previous analyses, but also detected interactions between Oct4 and signaling pathways. For example, van den Berg and colleagues found that Oct4 associated with Rbpi, the nuclear effector of the Notch signaling pathway - implying a connection between Oct4 and the Notch-regulated gene expression. In addition, both interactomes contain chromatinmodifying complexes, such as NuRD and SWI/SNF, representing links between epigenetic modifying complexes and pluripotency transcriptional factors. Despite substantial progress in understanding Oct4-centered protein interactomes in ESCs, there are significant discrepancies between these two studies [68]. Further investigation and detailed comparison are required to clarify the basis of the differences.

In addition to protein coding genes, noncoding RNA targets of Oct4 have been found. For example, in concert with Sox2, Oct4 positively regulates miR-302, a cluster of eight miRNAs expressed specifically in ESCs. One member of this cluster, miR-302a, inhibits the translation of cyclin $D_{1}$ (an important $G_{1}$ regulator) to maintain an ESC-specific cell cycle profile [69]. Moreover, a long noncoding RNA, AK028326, which was recently shown to be directly activated by Oct4, was observed to function as a coactivator of Oct4 in a regulatory feedback loop [70]. Functionally, the overexpression or knockdown of AK028326 changed the expression levels of pluripotency factors, as well as lineage-specific factors, indicating its functional role in determining the cell fate of ESCs. In addition, Oct4 also functions during X-chromosome reprogramming. It can directly binds Tsix and Xite (two regulatory noncoding RNA genes of the X-inactivation center) and also interacts with Ctcf (the X-chromosome inactivation trans-factor) to regulate $\mathrm{X}$-chromosome pairing and counting [71]. These studies expanded our knowledge of the Oct4-centered transcriptional regulatory network in pluripotent cells, and their results have elucidated new mechanisms associated with establishing and maintaining pluripotency.

Taken together, Oct4 interacts with other pluripotency factors - such as Nanog, Sox2, Sall4, Klf5, Zfp143, Zfp206, Esrrb, Dax1 and Tcfcp211 - to form autoregulatory and cross-regulatory loops and to maintain a pluripotent state. Interestingly, some of these factors, including Esrrb, Tcfcp211 and Dax1, depend on Oct4 for the efficient targeting of several of their shared sites [41], emphasizing the importance of coordination among pluripotency factors and the critical role of Oct4 in the maintenance of a pluripotent state. Additionally, Oct4 may recruit transcriptional repressive complexes, such as NuRD and PRC1, to the genomic sites of lineage-specific factors and prevent differentiation of pluripotent cells (Figure 2).

\section{Indispensable role of Oct4 in reprogramming}

The achievement of reprogramming by four defined transcription factors drew tremendous interest in the scientific field. The earliest reprogramming was achieved 


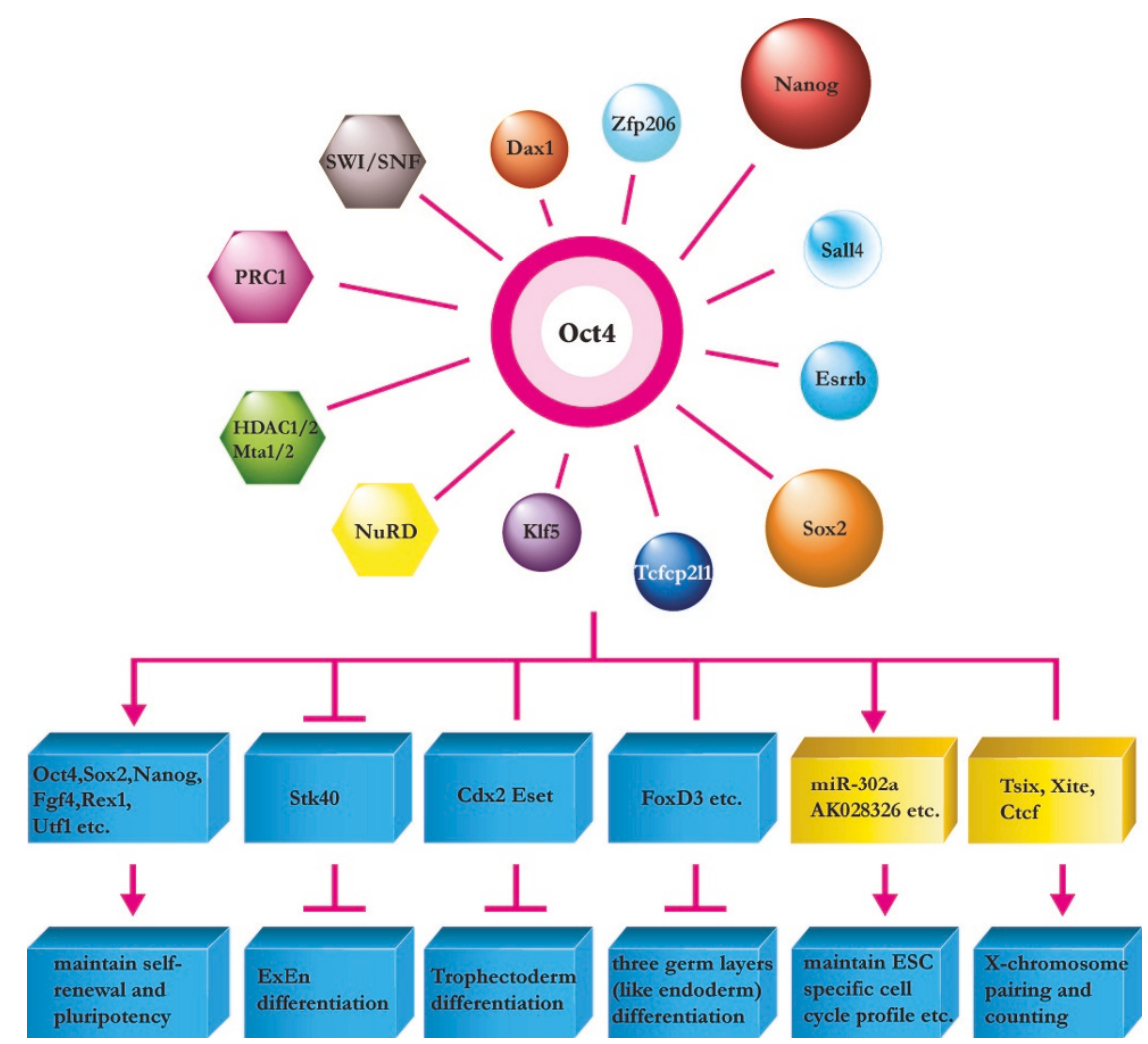

Figure 2. Oct4 interacts with various partners and regulates different target sets to carry out its functions. Depending on its associated partners, Oct4 can either activate or repress its target genes. When associated with factors such as Sox2, Nanog and Sall4 at regulatory elements, Oct4 usually exerts stimulatory effects on gene expression. Additionally, Oct4 can repress developmental genes through interacting with repressors (for example, NuRD and PRC1). Through regulating various targets, Oct4 has versatile effects on pluripotency: it maintains self-renewal and pluripotency by activating its own expression and that of factors such as Sox2 and Nanog; through modulating the expression or function of development-associated genes - such as Stk40, Cdx2, Eset and FoxD3 - Oct4 prevents the differentiation of pluripotent stem cells; it can also influence other aspects of embryonic stem cells (ESCs), including cell cycle and X-chromosome inactivation, through various effectors (for example, miR-302a, Ctcf). ExEn, extraembryonic endoderm.

using the Yamanaka factors (Oct4, Sox2, Klf4 and c-Myc) [2] or the Thomson factors (Oct4, Sox2, Nanog and Lin28) [3], both of which include Oct4. It was later found that some cell types express one or several reprogramming factors endogenously and require fewer factors for reprogramming. Other factors and some family members of reprogramming factors, as well as certain chemicals, promote the reprogramming process (reviewed in [23]). Noticeably, Oct 4 was required in all except two studies to derive induced pluripotent stem (iPS) cell lines: one study found that BIX-01294, an inhibitor of the G9a histone methyltransferase, could reprogram mouse neural progenitor cells in concert with Sox2, Klf4 and c-Myc [72]; the other study found that $\mathrm{Nr} 5 \mathrm{a} 2$ and its close family member Nr5a1 could replace Oct 4 in the reprogramming of mouse embryonic fibroblasts [73]. The efficiency of reprogramming was extremely low in both reports, however, and these substitutes might function through modulating Oct4 and Nanog expression. In addition, Fbx15 (a marker gene of undifferentiated ESCs that is dispensable for pluripotency in ESCs) was utilized as a reporter of reprogramming in the first generation of iPS cells. The derived iPS cell lines, however, were dissimilar to ESCs in several aspects and could not generate chimeras [2]. Further characterization of these lines found that the promoter of the endogenous Oct4 gene was still highly methylated. In later research, the state of the hypomethylated Oct4 promoter was used as an indicator of complete reprogramming, and the resultant iPS cell lines could not be distinguished from ESCs, further emphasizing the importance of Oct4 in regaining pluripotency [74]. Moreover, the derivation of iPS cell lines requires viral transfection, hampering their clinical application; one way of avoiding this problem is to use fewer reprogramming factors. Scholer's group successfully reprogrammed both mouse and human neural progenitors using only Oct4 [75,76], again highlighting the power of Oct4 in re-establishing pluripotency.

Having demonstrated the essential and critical role of Oct4 in regaining pluripotency, scientists have engaged 
in tremendous efforts to understand the underlying mechanisms of reprogramming, especially the roles of Oct4 during the process of reprogramming. Preliminary results showed that Oct4 plays an important role in activating ESC-specific genes by cooperating with Sox 2 and Klf4, and most of these genes are silenced in partially reprogrammed cells [77]. Moreover, Oct4 was reported to suppress the transcription of the epithelial mesenchymal transition mediator Snail to facilitate reprogramming [78]. Interestingly, a new strategy for Oct4 functions was recently suggested - that is, Oct4 specifically interacts with nuclear $\beta$-catenin and facilitates its proteasomal degradation, thus maintaining the undifferentiated state of ESCs [79]. The important conclusions from these studies are that Oct4 does not function alone and that a delicate balance among pluripotency factors defines the state of pluripotency in ESCs and embryonic cells. Similarly, regaining this balance is the key to successful reprogramming, which might, at least partially, explain why reprogramming efficiency is very low, even when four factors are efficiently transduced into somatic cells.

\section{Conclusion and perspective}

Since Oct4 was first identified in mice as an embryonic stem cell-specific and germline-specific transcription factor in 1990, studies have highlighted its importance in governing pluripotency. The complex regulation of Oct 4 expression further reflects the necessity to control its expression level precisely. The interest in Oct 4 increases primarily due to the indispensable role of Oct 4 in the generation of iPS cells. Nevertheless, a number of important issues remain to be addressed.

The study of gene expression profiling indicates that Oct4 primarily acts as an activator of gene expression [59]. In Oct4 protein interactomes, however, many Oct4associated partners have been identified as transcriptional repressors $[41,42,66,67]$. Notably, the coactivator p300 was found to be recruited to the cluster of Oct4, Sox 2 and Nanog using a chromatin immunoprecipitationseq approach [61], implying that p300 might play a role in Oct4-mediated transcription activation. Strangely, none of the recently identified Oct4-centered protein interaction networks contain p300.

How Oct4 connects to the basal transcriptional machinery also remains unclear. Van den Berg and colleagues showed the association of Esrrb with components of the basal transcriptional machinery, including the mediator complex, RNA polymerase II subunits and TATA box binding protein plus transcription-associated factors. The connection between Oct4 and the basal transcriptional machinery could thus be established through Esrrb, as the association of Oct4 with Esrrb has been documented [56].
Furthermore, it remains unclear how different dosages of Oct4 act to determine ESC fates. One possibility is that Oct4 associates with distinct partners at different dosages, provided that Oct 4 displays different affinities toward its partners at different expression levels. Achieving a comprehensive understanding of how different biological processes, such as transcriptional, posttranscriptional and epigenetic regulation, work together to maintain Oct4 at an appropriate level will also help to solve this puzzle. Another interesting and important question is why Oct4 expression is so critical in generating fully reprogrammed cells from somatic cells.

Clearly, the investigation of how Oct4 exerts its functions through regulating various targets is in its early stages, and this should be the focus of future research. In addition, employing an experimental design to study Oct4-associated proteins or target genes at a single-cell level in a dynamic manner will allow us to obtain a clearer picture of how Oct4 maintains and re-establishes pluripotency. We believe that these types of investigations and other related studies will fulfill the great promise of pluripotent stem cells in the near future.

\section{Abbreviations}

ESC, embryonic stem cell; Esrrb, estrogen-related receptor b; ICM, inner cell mass; iPS, induced pluripotent stem; miRNA, microRNA.

\section{Competing interests}

The authors declare that they have no competing interests.

\section{Acknowledgements}

The authors thank Dr Allen Chong for critical reading and other laboratory members for helpful suggestions during the preparation of the manuscript. The present study was supported by grants from the National Natural Science Foundation (30730051 and 30911130361 ), the National High Technology Research and Development Program of China (2006CB94390, 2007CB947904, 2007CB947101 and 2010CB945200), and the Shanghai Science \& Technology Developmental Foundations (08JC1413100 and 0754S21512).

\section{Author details}

'Key Laboratory of Stem Cell Biology, Institute of Health Sciences, Shanghai Institutes for Biological Sciences, Chinese Academy of Sciences/Shanghai JiaoTong University School of Medicine, 225 South Chongqing Road, Shanghai 200025, China. ${ }^{2}$ Shanghai Institute of Stem Cell Research, Shanghai JiaoTong University School of Medicine, 225 South Chongqing Road, Shanghai 200025, China. ${ }^{3}$ Graduate School of Chinese Academy of Sciences, 19 Yuquan Road, Beijing 100049, China.

\section{Published: 14 December 2010}

\section{References}

1. Waddington $\mathrm{CH}$ : The Strategy of the Genes: A Discussion of Some Aspects of Theoretical Biology. New York: Macmillan; 1957.

2. Takahashi K, Yamanaka S: Induction of pluripotent stem cells from mouse embryonic and adult fibroblast cultures by defined factors. Cell 2006, 126:663-676.

3. Yu J, Vodyanik MA, Smuga-Otto K, Antosiewicz-Bourget J, Frane JL, Tian S, Nie J, Jonsdottir GA, Ruotti V, Stewart R, Slukvin II, Thomson JA: Induced pluripotent stem cell lines derived from human somatic cells. Science 2007, 318:1917-1920.

4. Scholer HR, Ruppert S, Suzuki N, Chowdhury K, Gruss P: New type of POU domain in germ line-specific protein Oct-4. Nature 1990, 344:435-439.

5. Rosner MH, Vigano MA, Ozato K, Timmons PM, Poirier F, Rigby PW, Staudt LM: A POU-domain transcription factor in early stem cells and germ cells of the mammalian embryo. Nature 1990, 345:686-692. 
6. Okamoto K, Okazawa H, Okuda A, Sakai M, Muramatsu M, Hamada H: A novel octamer binding transcription factor is differentially expressed in mouse embryonic cells. Cell 1990, 60:461-472.

7. Wang X, Dai J: Concise review: isoforms of OCT4 contribute to the confusing diversity in stem cell biology. Stem Cells 2010, 28:885-893.

8. Herr W, Cleary MA: The POU domain: versatility in transcriptional regulation by a flexible two-in-one DNA-binding domain. Genes Dev 1995 9:1679-1693.

9. Yeom Yl, Fuhrmann G, Ovitt CE, Brehm A, Ohbo K, Gross M, Hubner K, Scholer HR: Germline regulatory element of Oct-4 specific for the totipotent cycle of embryonal cells. Development 1996, 122:881-894.

10. Nordhoff V, Hubner K, Bauer A, Orlova I, Malapetsa A, Scholer HR: Comparative analysis of human, bovine, and murine Oct-4 upstream promoter sequences. Mamm Genome 2001, 12:309-317.

11. Pesce M, Scholer HR: Oct-4: gatekeeper in the beginnings of mammalian development. Stem Cells 2001, 19:271-278

12. Pan GJ, Chang ZY, Scholer HR, Pei D: Stem cell pluripotency and transcription factor Oct4. Cell Res 2002, 12:321-329.

13. Lengner CJ, Camargo FD, Hochedlinger K, Welstead GG, Zaidi S, Gokhale S, Scholer HR, Tomilin A, Jaenisch R: Oct4 expression is not required for mouse somatic stem cell self-renewal. Cell Stem Cell 2007, 1:403-415.

14. Nichols J, Zevnik B, Anastassiadis K, Niwa H, Klewe-Nebenius D, Chambers I, Scholer $\mathrm{H}$, Smith A: Formation of pluripotent stem cells in the mammalian embryo depends on the POU transcription factor Oct4. Cell 1998, 95:379-391

15. Zafarana G, Avery SR, Avery K, Moore HD, Andrews PW: Specific knockdown of OCT4 in human embryonic stem cells by inducible short hairpin RNA interference. Stem Cells 2009, 27:776-782.

16. Li L, Sun L, Gao F, Jiang J, Yang Y, Li C, Gu J, Wei Z, Yang A, Lu R, Ma Y, Tang F, Kwon SW, Zhao Y, Li J, Jin Y: Stk40 links the pluripotency factor Oct4 to the Erk/MAPK pathway and controls extraembryonic endoderm differentiation. Proc Natl Acad Sci U S A 2010, 107:1402-1407.

17. Niwa H, Miyazaki J, Smith A G: Quantitative expression of Oct-3/4 defines differentiation, dedifferentiation or self-renewal of ES cells. Nat Genet 2000, 24:372-376.

18. Zeineddine D, Papadimou E, Chebli K, Gineste M, Liu J, Grey C, Thurig S, Behfar A, Wallace VA, Skerjanc IS, Puceat M: Oct-3/4 dose dependently regulates specification of embryonic stem cells toward a cardiac lineage and early heart development. Dev Cell 2006, 11:535-546.

19. Feldman N, Gerson A, Fang J, Li E, Zhang Y, Shinkai Y, Cedar H, Bergman Y: G9a-mediated irreversible epigenetic inactivation of Oct-3/4 during early embryogenesis. Nat Cell Biol 2006, 8:188-194.

20. Li JY, Pu MT, Hirasawa R, Li BZ, Huang YN, Zeng R, Jing NH, Chen T, Li E, Sasak $\mathrm{H}, \mathrm{XU}$ GL: Synergistic function of DNA methyltransferases Dnmt3a and Dnmt3b in the methylation of Oct4 and Nanog. Mol Cell Biol 2007 27:8748-8759.

21. Deshpande AM, Dai YS, Kim Y, Kim J, Kimlin L, Gao K, Wong DT: Cdk2ap1 is required for epigenetic silencing of Oct4 during murine embryonic stem cell differentiation. J Biol Chem 2009, 284:6043-6047.

22. Ding L, Paszkowski-Rogacz M, Nitzsche A, Slabicki MM, Heninger AK, de Vries I, Kittler R, Junqueira M, Shevchenko A, Schulz H, Hubner N, Doss MX, Sachinidis A, Hescheler J, lacone R, Anastassiadis K, Stewart AF, Pisabarro MT, Caldarelli A, Poser I, Theis M, Buchholz F: A genome-scale RNAi screen for Oct4 modulators defines a role of the Paf1 complex for embryonic stem cell identity. Cell Stem Cell 2009, 4:403-415.

23. Feng $\mathrm{B}, \mathrm{Ng} \mathrm{JH}$, Heng JC, $\mathrm{Ng} \mathrm{HH}$ : Molecules that promote or enhance reprogramming of somatic cells to induced pluripotent stem cells. Cell Stem Cell 2009, 4:301-312

24. Ben-Shushan E, Sharir H, Pikarsky E, Bergman Y: A dynamic balance between ARP-1/COUP-TFII, EAR-3/COUP-TFI, and retinoic acid receptor:retinoid X receptor heterodimers regulates Oct-3/4 expression in embryonal carcinoma cells. Mol Cell Biol 1995, 15:1034-1048.

25. Zhang X, Zhang J, Wang T, Esteban MA, Pei D: Esrrb activates Oct4 transcription and sustains self-renewal and pluripotency in embryonic stem cells. J Biol Chem 2008, 283:35825-35833.

26. Yang HM, Do HJ, Kim DK, Park JK, Chang WK, Chung HM, Choi SY, Kim JH: Transcriptional regulation of human Oct4 by steroidogenic factor-1. J Cell Biochem 2007, 101:1198-1209.

27. Gu P, Goodwin B, Chung AC, Xu X, Wheeler DA, Price RR, Galardi C, Peng L, Latour AM, Koller BH, Gossen J, Kliewer SA, Cooney AJ: Orphan nuclear receptor $\mathrm{LRH}-1$ is required to maintain Oct4 expression at the epiblast stage of embryonic development. Mol Cell Biol 2005, 25:3492-3505.

28. Fuhrmann G, Chung AC, Jackson KJ, Hummelke G, Baniahmad A, Sutter J, Sylvester I, Scholer HR, Cooney AJ: Mouse germline restriction of Oct4 expression by germ cell nuclear factor. Dev Cell 2001, 1:377-387.

29. Park SW, Hu X, Gupta P, Lin YP, Ha SG, Wei LN: SUMOylation of Tr2 orphan receptor involves Pml and fine-tunes Oct4 expression in stem cells. Nat Struct Mol Biol 2007, 14:68-75.

30. Gupta P, Ho PC, Huq MM, Ha SG, Park SW, Khan AA, Tsai NP, Wei LN: Retinoic acid-stimulated sequential phosphorylation, PML recruitment, and SUMOylation of nuclear receptor TR2 to suppress Oct4 expression. Proc Natl Acad SciU S A 2008, 105:11424-11429.

31. Boyer LA, Lee TI, Cole MF, Johnstone SE, Levine SS, Zucker JP, Guenther MG, Kumar RM, Murray HL, Jenner RG, Gifford DK, Melton DA, Jaenisch R, Young RA: Core transcriptional regulatory circuitry in human embryonic stem cells. Cell 2005, 122:947-956.

32. Loh YH, Wu Q, Chew JL, Vega VB, Zhang W, Chen X, Bourque G, George J, Leong B, Liu J, Wong KY, Sung KW, Lee CW, Zhao XD, Chiu KP, Lipovich L, Kuznetsov VA, Robson P, Stanton LW, Wei CL, Ruan Y, Lim B, Ng HH: The Oct4 and Nanog transcription network regulates pluripotency in mouse embryonic stem cells. Nat Genet 2006, 38:431-440.

33. Chew JL, Loh YH, Zhang W, Chen X, Tam WL, Yeap LS, Li P, Ang YS, Lim B, Robson $\mathrm{P}, \mathrm{Ng} \mathrm{HH}$ : Reciprocal transcriptional regulation of Pou5f1 and Sox2 via the Oct4/Sox2 complex in embryonic stem cells. Mol Cell Bio/ 2005, 25:6031-6046.

34. Zhang J, Tam WL, Tong GQ, Wu Q, Chan HY, Soh BS, Lou Y, Yang J, Ma Y, Chai L, $\mathrm{Ng} \mathrm{HH}$, Lufkin T, Robson P, Lim B: Sall4 modulates embryonic stem cell pluripotency and early embryonic development by the transcriptional regulation of Pou5f1. Nat Cell Biol 2006, 8:1114-1123.

35. Yang J, Chai L, Fowles TC, Alipio Z, Xu D, Fink LM, Ward DC, Ma Y: Genomewide analysis reveals Sall4 to be a major regulator of pluripotency in murine-embryonic stem cells. Proc Natl Acad SciU S A 2008, 105:19756-19761.

36. Xu N, Papagiannakopoulos T, Pan G, Thomson JA, Kosik KS: MicroRNA-145 regulates OCT4, SOX2, and KLF4 and represses pluripotency in human embryonic stem cells. Cell 2009, 137:647-658

37. Tay Y, Zhang J, Thomson AM, Lim B, Rigoutsos I: MicroRNAs to Nanog, Oct4 and Sox 2 coding regions modulate embryonic stem cell differentiation. Nature 2008, 455:1124-1128.

38. Qiu C, Ma Y, Wang J, Peng S, Huang Y: Lin28-mediated post-transcriptional regulation of Oct4 expression in human embryonic stem cells. Nucleic Acids Res 2010, 38:1240-1248.

39. Brehm A, Ohbo K, Scholer $\mathrm{H}$ : The carboxy-terminal transactivation domain of Oct- 4 acquires cell specificity through the POU domain. Mol Cell Biol 1997, 17:154-162

40. Webster DM, Teo CF, Sun Y, Wloga D, Gay S, Klonowski KD, Wells L, Dougan ST: O-GICNAc modifications regulate cell survival and epiboly during zebrafish development. BMC Dev Bio/ 2009, 9:28.

41. van den Berg DL, Snoek T, Mullin NP, Yates A, Bezstarosti K, Demmers J, Chambers I, Poot RA: An Oct4-centered protein interaction network in embryonic stem cells. Cell Stem Cell 2010, 6:369-381

42. Pardo M, Lang B, Yu L, Prosser H, Bradley A, Babu MM, Choudhary J: An expanded Oct 4 interaction network: implications for stem cell biology, development, and disease. Cell Stem Cell 2010, 6:382-395.

43. Xu HM, Liao B, Zhang QJ, Wang BB, Li H, Zhong XM, Sheng HZ, Zhao YX, Zhao YM, Jin Y: Wwp2, an E3 ubiquitin ligase that targets transcription factor Oct-4 for ubiquitination. J Biol Chem 2004, 279:23495-23503.

44. Liao B, Jin Y: Wwp2 mediates Oct4 ubiquitination and its own autoubiquitination in a dosage-dependent manner. Cell Res 2010, 20:332-344.

45. Xu H, Wang W, Li C, Yu H, Yang A, Wang B, Jin Y: WWP2 promotes degradation of transcription factor OCT4 in human embryonic stem cells. Cell Res 2009, 19:561-573.

46. Nichols J, Smith A: Naive and primed pluripotent states. Cell Stem Cell 2009, 4:487-492.

47. Wei F, Scholer HR, Atchison ML: Sumoylation of Oct4 enhances its stability, DNA binding, and transactivation. J Biol Chem 2007, 282:21551-21560.

48. Zhang Z, Liao B, Xu M, Jin Y: Post-translational modification of POU domain transcription factor Oct-4 by SUMO-1. FASEB J 2007, 21:3042-3051.

49. Rodda DJ, Chew JL, Lim LH, Loh YH, Wang B, Ng HH, Robson P. Transcriptional regulation of nanog by OCT4 and SOX2. J Biol Chem 2005, 280:24731-24737.

50. Ambrosetti DC, Basilico C, Dailey L: Synergistic activation of the fibroblast 
growth factor 4 enhancer by Sox 2 and Oct- 3 depends on protein-protein interactions facilitated by a specific spatial arrangement of factor binding sites. Mol Cell Biol 1997, 17:6321-6329.

51. Nishimoto M, Fukushima A, Okuda A, Muramatsu M: The gene for the embryonic stem cell coactivator UTF1 carries a regulatory element which selectively interacts with a complex composed of Oct-3/4 and Sox-2. Mol Cell Biol 1999, 19:5453-5465.

52. Wang $Z X$, Teh CH, Kueh JL, Lufkin T, Robson P, Stanton L W: Oct4 and Sox2 directly regulate expression of another pluripotency transcription factor, Zfp206, in embryonic stem cells. J Biol Chem 2007, 282:12822-12830.

53. Kashyap V, Rezende NC, Scotland KB, Shaffer SM, Persson JL, Gudas L Mongan NP: Regulation of stem cell pluripotency and differentiation involves a mutual regulatory circuit of the NANOG, OCT4, and SOX2 pluripotency transcription factors with polycomb repressive complexes and stem cell microRNAs. Stem Cells Dev 2009, 18:1093-1108.

54. Chambers I, Tomlinson SR: The transcriptional foundation of pluripotency. Development 2009, 136:2311-2322.

55. Kuroda T, Tada M, Kubota H, Kimura H, Hatano SY, Suemori H, Nakatsuji N, Tada T: Octamer and Sox elements are required for transcriptional cis regulation of Nanog gene expression. Mol Cell Biol 2005, 25:2475-2485.

56. van den Berg DL, Zhang W, Yates A, Engelen E, Takacs K, Bezstarosti K, Demmers J, Chambers I, Poot RA: Estrogen-related receptor beta interacts with Oct4 to positively regulate Nanog gene expression. Mol Cell Biol 2008, 28:5986-5995.

57. Yu HB, Kunarso G, Hong FH, Stanton LW: Zfp206, Oct4, and Sox2 are integrated components of a transcriptional regulatory network in embryonic stem cells. J Biol Chem 2009, 284:31327-31335.

58. Matoba R, Niwa H, Masui S, Ohtsuka S, Carter MG, Sharov AA, Ko MS: Dissecting Oct3/4-regulated gene networks in embryonic stem cells by expression profiling. PLoS One 2006, 1:e26.

59. Sharov AA, Masui S, Sharova LV, Piao Y, Aiba K, Matoba R, Xin L, Niwa H, Ko MS: Identification of Pou5f1, Sox2, and Nanog downstream target genes with statistical confidence by applying a novel algorithm to time course microarray and genome-wide chromatin immunoprecipitation data. BMC Genomics 2008, 9:269.

60. Chavez L, Bais AS, Vingron M, Lehrach H, Adjaye J, Herwig R: In silico identification of a core regulatory network of OCT4 in human embryonic stem cells using an integrated approach. BMC Genomics 2009, 10:314.

61. Chen X, Xu H, Yuan P, Fang F, Huss M, Vega VB, Wong E, Orlov YL, Zhang W, Jiang J, Loh YH, Yeo HC, Yeo ZX, Narang V, Govindarajan KR, Leong B, Shahab A, Ruan Y, Bourque G, Sung WK, Clarke ND, Wei CL, Ng HH: Integration of external signaling pathways with the core transcriptional network in embryonic stem cells. Cell 2008, 133:1 106-1117.

62. Kim J, Chu J, Shen X, Wang J, Orkin SH: An extended transcriptional network for pluripotency of embryonic stem cells. Cell 2008, 132:1049-1061.

63. Niwa $H$, Toyooka Y, Shimosato D, Strumpf D, Takahashi K, Yagi R, Rossant J: Interaction between Oct $3 / 4$ and $\mathrm{Cd} \times 2$ determines trophectoderm differentiation. Cell 2005, 123:917-929.

64. Yuan P, Han J, Guo G, Orlov YL, Huss M, Loh YH, Yaw LP, Robson P, Lim B, Ng $\mathrm{HH}$ : Eset partners with Oct4 to restrict extraembryonic trophoblast lineage potential in embryonic stem cells. Genes Dev 2009, 23:2507-2520.

65. Guo Y, Costa R, Ramsey H, Starnes T, Vance G, Robertson K, Kelley M, Reinbold $\mathrm{R}$, Scholer H, Hromas R: The embryonic stem cell transcription factors Oct-4 and FoxD3 interact to regulate endodermal-specific promoter expression. Proc Natl Acad Sci U S A 2002, 99:3663-3667.
66. Wang J, Rao S, Chu J, Shen X, Levasseur DN, Theunissen TW, Orkin SH: A protein interaction network for pluripotency of embryonic stem cells. Nature 2006, 444:364-368.

67. Liang J, Wan M, Zhang Y, Gu P, Xin H, Jung SY, Qin J, Wong J, Cooney AJ, Liu D, Songyang Z: Nanog and Oct4 associate with unique transcriptional repression complexes in embryonic stem cells. Nat Cell Biol 2008, 10:731-739.

68. Lemischka IR: Hooking up with Oct4. Cell Stem Cell 2010, 6:291-292.

69. Card DA, Hebbar PB, Li L, Trotter KW, Komatsu Y, Mishina Y, Archer TK: Oct4/ Sox2-regulated miR-302 targets cyclin D1 in human embryonic stem cells. $\mathrm{Mol}$ Cell Biol 2008, 28:6426-6438

70. Sheik Mohamed J, Gaughwin PM, Lim B, Robson P, Lipovich L: Conserved long noncoding RNAs transcriptionally regulated by Oct4 and Nanog modulate pluripotency in mouse embryonic stem cells. RNA 2010 16:324-337.

71. Donohoe ME, Silva SS, Pinter SF, Xu N, Lee JT: The pluripotency factor Oct4 interacts with $\mathrm{Ctcf}$ and also controls X-chromosome pairing and counting. Nature 2009, 460:128-132.

72. Shi Y, Do JT, Desponts C, Hahm HS, Scholer HR, Ding S: A combined chemical and genetic approach for the generation of induced pluripotent stem cells. Cell Stem Cell 2008, 2:525-528.

73. Heng JC, Feng B, Han J, Jiang J, Kraus P, Ng JH, Orlov YL, Huss M, Yang L, Lufkin T, Lim B, Ng HH: The nuclear receptor $\mathrm{Nr} 5 \mathrm{a} 2$ can replace Oct4 in the reprogramming of murine somatic cells to pluripotent cells. Cell Stem Cell 2010, 6:167-174

74. Wernig M, Meissner A, Foreman R, Brambrink T, Ku M, Hochedlinger K, Bernstein $B E$, Jaenisch $R$ : In vitro reprogramming of fibroblasts into a pluripotent ES-cell-like state. Nature 2007, 448:318-324.

75. Kim JB, Sebastiano V, Wu G, Arauzo-Bravo MJ, Sasse P, Gentile L, Ko K, Ruau D, Ehrich M, van den Boom D, Meyer J, Hubner K, Bernemann C, Ortmeier C, Zenke M, Fleischmann BK, Zaehres H, Scholer HR: Oct4-induced pluripotency in adult neural stem cells. Cell 2009, 136:411-419.

76. Kim JB, Greber B, Arauzo-Bravo MJ, Meyer J, Park KI, Zaehres H, Scholer HR: Direct reprogramming of human neural stem cells by OCT4. Nature 2009, 461:649-653.

77. Sridharan R, Tchieu J, Mason MJ, Yachechko R, Kuoy E, Horvath S, Zhou Q Plath K: Role of the murine reprogramming factors in the induction of pluripotency. Cell 2009, 136:364-377.

78. Li R, Liang J, Ni S, Zhou T, Qing X, Li H, He W, Chen J, Li F, Zhuang Q, Qin B, Xu J, Li W, Yang J, Gan Y, Qin D, Feng S, Song H, Yang D, Zhang B, Zeng L, Lai L, Esteban M A, Pei D: A mesenchymal-to-epithelial transition initiates and is required for the nuclear reprogramming of mouse fibroblasts. Cell Stem Cell 2010, 7:51-63.

79. Abu-Remaileh M, Gerson A, Farago M, Nathan G, Alkalay I, Zins Rousso S, Gur M, Fainsod A, Bergman Y: Oct-3/4 regulates stem cell identity and cell fate decisions by modulating Wnt/beta-catenin signalling. EMBO J 2010, 29:3236-3248.

doi:10.1186/scrt39

Cite this article as: Shi G, Jin Y: Role of Oct4 in maintaining and regaining

stem cell pluripotency. Stem Cell Research \& Therapy 2010, 1:39. 